\title{
História e memória em Goiás no século XIX uma consciência da mágoa e da esperança*
}

\author{
History and memory in Goiás \\ in the nineteenth century \\ an awareness of the hurt and hope
}

\author{
NOÉ FREIRE SANDES** \\ Faculdade de História \\ Universidade Federal de Goiás \\ Goiânia (GO) \\ Brasil \\ Cristiano alencar arRais*** \\ Faculdade de História \\ Universidade Federal de Goiás \\ Goiânia (GO) \\ Brasil
}

RESUMO Este artigo propõe identificar um modelo explicativo para a escrita da história de Goiás no século XIX. Este modelo implicava numa relação ambîgua em relação ao passado, revelando uma consciência histórica marcada pelo reforço do vínculo com a nação, pela negativação do período colonial e pela adoção de um critério moral para julgar o passado. Ao dialogar intensamente com a memória regional quase ao ponto de fundir-se com ela, a escrita da história de Goiás conclamava o Estado a participar da construção, não da Nação, já esboçada nos escritos do Instituto Histórico

\footnotetext{
* Artigo recebido em: 12/09/2012. Aprovado em: 02/09/2013.

** Doutor em História pela Universidade de São Paulo. Contato: noefsandes@uol.com.br.

*** Doutor em História pela Universidade Federal de Minas Gerais. Contato: cpaarrais@gmail.com.
} 
e Geográfico Brasileiro (IHGB), mas da região, na esperança de reconstruir os seus vínculos identitários.

Palavras-chave memória, historiografia, região

ABSTRACT This article intends to identify an explanatory model to writing the Goiás history, in the nineteenth century. This model involved an ambiguous relationship with the past, revealing an historical awareness characterized by strengthening of link with the nation, by negativation of the colonial period, and the adoption of a moral criterion for judge the past. By dialoguing intensively with regional memory nearly to the point to fuse up with it, the writing of Goiás history called on the State to participate in the construction, not the Nation, as outlined in the writings of Instituto Histórico e Geográfico Brasileiro (IHGB), but of the region in hopes to reconstruct their identity links.

Keywords memory, historiography, region

\section{Introdução}

A reflexão em torno do conhecimento da história regional está associada a três conceitos fundamentais: a Memória (a experiência humana presentificada no tempo), a História (o produto escriturário da tensão criada entre o passado, o historiador e sua cultura) e a Região (o discurso da diferença, que reivindica a legitimidade do específico e de seus critérios de eleição e, ao mesmo tempo, a autoridade de sua associação com o mundo). A história, enquanto representação do passado, acaba por elidir a noção de experiência dos sujeitos envolvidos no enfrentamento do seu próprio tempo. A historiografia oitocentista retirou a inteligibilidade reinante na sociedade colonial, redefinindo o sentido da relação entre os súditos e a coroa portuguesa. Doravante, o passado será percebido por um viés negativo, realçando, apenas, a ação predatória da metrópole na exploração do território goiano. Tal estratégia anuncia uma prática costumeira, o uso político do passado.

Entretanto, em Goiás esse expediente fixou na memória histórica uma inteligibilidade delineada pelo esgotamento da produção de ouro. Faz-se necessário, portanto, abordar de modo compreensivo a história da região no intuito de redimensionar a fronteira do pensável, enquanto consciência histórica, para além de uma suposta experiência da decadência ou da abastança que teria norteado a experiência social dos homens daquela época. Ou seja, trata-se de refletir sobre a difícil negociação operada em torno da relação entre essa memória e a historiografia regional contemporânea. Para tanto, faz-se necessário adentrar à fronteira onde a experiência dialoga com a representação social, por meio das marcas e vestígios deixados pelos 
primeiros escritores da história de Goiás. Essa será a estratégia analítica a guiar esse empreendimento investigativo.

\section{Nação, região e a historiografia brasileira do século XIX}

Um dos textos historiográficos mais conhecidos acerca da formação da nação brasileira é Como se deve escrever a história do Brasil, do viajante e biólogo Phillipe Von Martius. Este opúsculo, como bem sabemos, é de suma importância para o projeto de escrita da história do Instituto Histórico e Geográfico Brasileiro (IHGB) na medida em que responde às inquietações decorrentes do processo de constituição do Estado nacional. A fórmula de Martius, narrativa, permeada pelo "encontro" entre as três raças, abriu um campo representativo da nacionalidade, sob o domínio da estética romântica. Entre o indígena, o escravo e o colonizador firmar-se-ia um sistema de controle das diferenças, garantia de governabilidade para o Estado Monárquico. O IHGB voltava o olhar para o passado em busca de pistas que valorizassem os vestígios do mundo indígena e da ação colonizadora, abrindo um caminho para a ordenação da imaginação historiadora sobre a identidade nacional.

Contra a força centrífuga dos interesses regionalistas, Martius alertava para os riscos de uma história cuja demarcação representasse uma ameaça ao sentido de unidade política construída pelo Império. Isso porque, apesar de estarem repletas de fatos importantes que esclarecessem muitos acontecimentos particulares, tais histórias "não satisfazem ainda as exigências da verdadeira historiografia porque se ressentem demais de certo espírito das crônicas" prejudicando, segundo o autor, "o interesse da narração" e confundindo "o juízo claro do leitor sobre o essencial da relação". Para superar o caráter diverso da natureza, dos usos e dos costumes de uma população distribuída por tão vasto território e, ao mesmo tempo, incorporálas à representação política do império uno e harmônico, uma narrativa historiográfica modelar deveria provar sua eficácia na medida em que conseguisse convencer seus leitores "da necessidade de uma Monarquia em um país onde há tão grande número de escravos". E sentencia ao final de seu opúsculo:

Cada uma das partes do Império deve tornar-se cara às outras; deve procurar-se provar que o Brasil, país tão vasto e rico em fontes variadíssimas de ventura e prosperidade civil, alcançará o seu mais favorável desenvolvimento, se chegar, firmes os seus habitantes na sustentação da Monarquia; a estabelecer por uma sábia organização entre todas as províncias, relações recíprocas. ${ }^{1}$

1 MARTIUS, Carl Friedrich von. Como se deve escrever a História do Brasil. Jornal do Instituto Histórico e Geográphico Brazileiro, Rio de Janeiro, n.24, p.402, 1844. Disponível em: <http://www.ingb.org.br/rihgb.php?s=p>. Acesso em: 20 mai. 2012. 
Mesmo Cunha Matos, em sua Dissertação acerca do sistema de escrever a história antiga e moderna do império do Brasil, publicado postumamente na revista do IHGB em 1863, apesar de incitar que "indaguemos em primeiro lugar a história particular ou das províncias, para com bons materiaes escrevermos a história geral do império brasileiro", o faz não porque seja uma voz dissonante dentro do Instituto. ${ }^{2} \mathrm{O}$ faz sim, porque reforça o mesmo projeto unitário que tinha no jovem imperador seu ícone: "como será possível escrever a historia philosophica do Brasil tomando por pharól os livros estrangeiros impressos antes da declaração da independência do império?", indagava o velho militar. É que não existiam relatos dignos de confiança a partir do qual se pudesse conceber essa história filosófica do império brasileiro, mas apenas um "imenso fardel de escriptos inexactos, insulsos, indigestos e fabulosos", produzidos por estrangeiros, anteriores à Independência e repletos de preconceitos contra a jovem nação.

Os mesmos traços cívicos dessa história filosófica também são observados nos escritos de Martius, que traduz em sua "lei particular das forças diagonais" um projeto historiográfico que pragmaticamente indica a superação do conflito racial (a conhecida fórmula de incorporação da matriz africana e indígena à ação civilizadora branca) que é também geopolítico. Martius, por meio de sua visão totalizante, atualiza a herança da coroa portuguesa encontrando na unidade territorial do império o nexo entre o presente e o passado. Por isso é que às regiões era relegado um papel secundário e complementar à história da nação, na medida em que a especificidade local é ressaltada apenas naquilo que "houver de verdadeiramente importante e significativo para a história". "Procedendo assim", completa o botânico, "não se devia principiar de novo [a história] de cada província, mas (...) se repetir". ${ }^{3}$

Certamente a fórmula pensada por Martius para examinar a região possuía profundas afinidades com o projeto unitarista do Segundo Império, que encontrava no IHGB um eco para suas aspirações. Nesse sentido, para além da finalidade de "coligir e methodisar os documentos históricos e geográficos interessantes á história do Brazil", como esclareceu a carta escrita em 16 de agosto de 1838, assinada por Raymundo José da Cunha Mattos e Januário da Cunha Barboza, quando propuse-

2 "por ora não convém, nem é possível escrever de um só jacto a historia geral do império do Brasil, que seja digna d'elle e faça honra aos membros d'este Instituto, que de tal tarefa houverem de ser encarregados. Pela parte que me toca declaro francamente que se a sorte ou a votação por escrutínio recahir em mim para trabalhar in solidum ou como colaborador em uma empresa tão gigantesca, eu me ostentarei inhabilitado, e recusarei aceitar essa honrosa comissão, para não ter de representar um papel desagradável e muito em desabono do Instituto Historico"; MATTOS, Raymundo José da Cunha. Dissertação acerca do systema de escrever a história antiga e moderna do Império do Brasil. Revista Trimensal do Instituto Histórico e Geográfico Brasileiro, Rio de Janeiro, Tomo 26, p.122, 1863. Disponível em: <http://www.ingb.org.br/rihgb.php?s=p>. Acesso em: 10 abr. 2012.

3 MARTIUS, Carl Friedrich von. Como se deve escrever a História do Brasil, p.400. 
ram criar o Instituto, ${ }^{4}$ consumava-se também um projeto de nação para o Brasil. Como bem lembrou Manoel Salgado Guimarães em seu estudo clássico, "o projeto de história nacional deveria dar conta da totalidade, construindo a Nação em sua diversidade e multiplicidade de aspectos". 5 Na carta enviada por Varnhagen ao Imperador, explicando os motivos que o levaram a escrever sua História Geral do Brasil, em 1854, este projeto já estava cristalizado:

Era para ir assim enfeixando-as [as províncias] todas e fazendo bater os corações dos de umas províncias em favor dos das outras, infiltrando a todos nobres sentimentos de patriotismo de nação, único sentimento que é capaz de desterrar o provincialismo excessivo, do modo que desterra o egoísmo, levando-nos a morrer pela pátria ou pelo soberano que personifica seus interesses, sua honra e sua glória. ${ }^{6}$

Varnhagen não era o único a pensar a relação pragmática entre escrita da história e identidade nacional. Foi Januário da Cunha Barbosa quem sentenciou que a história,

tornando-lhe presente a experiência dos séculos passados, ministra-lhe conselhos tão seguros como desinteressados, que lhe aclaram os caminhos que deve seguir, os escolhos que deve evitar, e o seguro porto, a que uma sólida manobra pode felizmente fazer chegar a nau do Estado. ${ }^{7}$

Dessa forma, e seguindo ainda o caminho aberto por Guimarães, o projeto de identidade nacional sustentado pelo IHGB situava a questão regional como um tema, ao mesmo tempo constantemente visitado nos estudos apresentados na revista, ${ }^{8}$ mas também submetido à concepção de história nacional:

No tratamento da questão, é privilegiada a perspectiva de considerar as regiões não nas suas especificidades - descartando com isso a polêmica do regionalismo - mas na sua intrínseca organicidade ao conjunto nacional. O fato de que é a partir do IHGB no Rio de Janeiro que a leitura dessas histórias regionais será

4 BARBOSA, Januário da Cunha, MATTOS, Raymundo José da Cunha. Proposta. Revista Trimensal do Instituto Histórico e Geográfico Brazileiro, Rio de Janeiro, Tomo I, n.1, p.6, 1839. Disponível em: <http://www.ihgb.org.br/ rihgb.php?s $=$ p>. Acesso em: 21 abr. 2012.

5 GUIMARÃES, Luiz Salgado. Nação e civilização nos trópicos: o Instituto Histórico e Geográfico Brasileiro e o projeto de uma história nacional. Estudos Históricos, v.1, n.1, p.16, 1988

6 GUIMARÃES, Luiz Salgado. Nação e civilização nos trópicos, p.18.

7 BARBOSA, Januário da Cunha. Relatório do Secretário Perpétuo. Revista Trimensal do Instituto Histórico e Geográfico Brasileiro, Rio de Janeiro, Tomo II (Suplemento), p.587. Disponível em: <http://www.ingb.org.br/rihgb.php?s=p>. Acesso em: 21 abr. 2012.

8 Além da perceptível ênfase nos estudos regionais, entre 1839 e 1850, da totalidade de artigos publicados na revista do IHGB, três províncias concentram a maior parte dos textos: Rio de Janeiro com 19\%, Bahia com 18\% e Minas Gerais (16\%). As três províncias concentravam mais de $50 \%$ do recorte geográfico das publicações da revista. Goiás ocupava 5\% do total da produção de artigos. Cf.: BENTIVÓGLIO, Júlio César. Lugares da História no Brasil imperial: institucionalização da pesquisa histórica e perfil da produção historiográfica nas páginas da Revista do Instituto Histórico e Geográfico Brasileiro. Anais do Simpósio Nacional de História da Historiografia. Mariana: UFOP, 2011. 
empreendida, reunindo, assim, na capital da monarquia todos os conhecimentos relativos às províncias, é expressão evidente da existência, no interior da instituição, de um projeto intelectual claramente centralista. ${ }^{9}$

O centralismo do projeto de escrita da história oitocentista exigia a formação de uma rede de institutos regionais, condição fundamental para que se ordenassem as representações da nação. Em Goiás, o gabinete literário, fundado em 1861, cumpriu a função similar à dos institutos históricos, sobretudo no que diz respeito à guarda de documentação e a propagação do conhecimento histórico; entretanto fugia às suas expectativas apontar, tal qual fizera o IHGB, uma direção para a escrita da história regional, tarefa que seria encarada, no século XX, por Americano do Brasil. ${ }^{10}$

\section{O modelo explicativo da experiência regional}

O pacto imperial foi fruto de uma complexa negociação, precedida muitas vezes por atos de força, entre províncias e a Corte. Mas em meio às abertas disputas pelo poder as elites políticas não se afastaram da proposição de um projeto unitário para o Brasil. A dificuldade residia, justamente, na definição clara dos papéis e da margem de autonomia reservada às províncias, como demonstram as revoltas regenciais. A questão torna-se ainda mais complexa em regiões marcadas por diminuto fluxo econômico, desgarradas do todo do qual, pretensamente, faziam parte. Nelas, percebese a presença de uma luminosidade opaca que mais esconde do que demarca o contorno da presumida unidade territorial: a nação está esboçada, mas necessita de capilaridade para fixar-se nos territórios provinciais.

A maneira como uma experiência social associada à presença e à ausência do ouro fixou-se na representação histórica de Goiás é exemplar. Este modelo representacional não é desconhecido de outras regiões brasileiras: uma sociedade ordenada pelo brilho do valioso metal que se defrontou, com rapidez, com o seu esgotamento. Um brilho natimorto, explicável retrospectivamente pela falta de experiência dos mineiros, pela pilhagem da antiga Metrópole - pois o passado era visado como obra de destruição - pelas leis inadequadas, processos irregulares de extração, ambição em demasia dos mineiros etc. Naquele ambiente, restava, portanto, tatear entre passado e presente, exigindo que o Estado Imperial minorasse o sentimento de abandono que vigorava nas terras do Brasil Central.

Essa perspectiva se apresenta claramente nos escritos de cronistas, viajantes e nos relatórios dos Presidentes de Província. Saint Hilaire (1819) fala em "grande decadência" e "profunda apatia em que estão imersos"

9 GUIMARÃES, Luiz Salgado. Nação e civilização nos trópicos, p.23-24.

10 RIBEIRO, Miriam Bianca Amaral. Cultura histórica e história ensinada em Goiás (1846-1934). Goiânia: Universidade Federal de Goiás, 2011 (História, Tese de doutorado). 
os habitantes de Goiás, Rodrigues Jardim (1835) julga as estradas da província como "sofríveis", assim como descreveu Camargo Fleury (1837) "em péssimo estado", Pohl (1817) refere-se aos "caminhos esburacados" e Castelnau (1843) ao "mau estado dos caminhos". Foi também Rodrigues Jardim quem caracterizou a dinâmica social regional: "o ocio e a falta de política em hum Paiz onde se pode viver sem trabaliar tem também concorrido para a diminuição da abundância, que nelle se disfructava", no que é acompanhado por Pohl "enquanto tem uns vinténs no bolso, não mexem com as mãos". D'Alincourt (1818) descreve os habitantes de Goiás como "dominados pela preguiça e demasiadamente entregues aos prazeres sexuais e bem diferentes são as causas que os têm conduzido a tão deplorável estado"; e para Taunay (1876) "a população (...) vive vida lânguida e desanimada". Mesmo os escritos de Couto Magalhães (1863), que procuram fugir às lamentações e aos pedidos de auxílio, comuns à maioria dos relatórios provinciais, não deixam de atestar o contraste entre o potencial econômico não explorado e a degeneração moral dos habitantes de Goiás: "aqui a vida se escoa gemendo constantemente", sentencia o jovem presidente da província. ${ }^{11}$

Essa é, em suma, a visão deixada por viajantes, artistas e funcionários sobre Goiás. Seria o caso, então, de confrontar estes relatos com as histórias construídas neste período? Silva e Souza, que chegou a Goiás em 1790 e participou daquele rico campo de experiência e fundou o mais importante marco memorial sobre a região, toma estes elementos como princípios explicativos de sua narrativa sobre Goiás. Em 1814, publicou uma Memória sobre o descobrimento, governo, população e cousas mais notáveis da Capitania de Goyaz, que descreveu o esplendor da mineração e a crise da decadência - econômica mas também moral, que lançou "nos braços da ociosidade aquelle amor ao trabalho e patriotismo, que prefere ao interesse próprio o bem comum". Seu trabalho reconstrutivo não é uma mera reunião de impressões pessoais, como pode-se imputar aos viajantes:

Eis aqui tudo o que a respeito de Goyaz pude descobrir no curto espaço de pouco mais de dous mezes, no meio da confusão em que estavam estas notícias; e nem devo duvidar que, apezar da minha diligencia, em alguns pontos me falte a exacção. Mas quem reflectir que não sahi da capital, que não entrei na secretaria e nos archivos que desejava, e que apenas mendiguei noticias dos que viajavam com os olhos menos fechados, de livros em alguns cartórios, e papeis que sem critica existiam em diferentes mãos particulares, conhecerá o trabalho que tive, que fiz quanto me foi possível, e que assim mesmo talvez sirva ao publico, estimulando a outros mais hábeis a escreverem a este respeito. ${ }^{12}$

11 CHAUL, Nasr Fayad. Os caminhos dos viajantes. In.: Caminhos de Goiás: da construção da decadência aos limites da modernidade. Goiânia: Editora UFG, 1997, p.35-68.

12 SOUZA, Luiz Antônio da Silva e. Memória do descobrimento, governo, população e cousas mais notáveis da Capitania de Goyaz (1814). Goiânia: Editora UFG, 1998, p.138. 
É um trabalho que, se por um lado, ressente de fontes, por outro lado, é próspero no interesse pelo passado como princípio explicativo do presente. A dupla tensão que envolve a representação historiadora está disposta em seu texto. A primeira, reconstrutiva das sequencias temporais e das relações causais entre os eventos através da empresa heurística e de crítica das fontes. A segunda, memorialista, porque para além da proposição de uma sequencia para os acontecimentos, denota-se uma cadeia causal que orienta sua representação do passado: é com os olhos no presente de decadência econômica e atraso que o memorialista estabelece seus critérios de julgamento sobre o passado, mas também suas expectativas de transformação. O passado não é visto como uma época áurea:

Tendo as melhores proporções para se engrandecer e felicitar os seus colonos, correu em menos de um século do esplendor do seu princípio para a crise da decadência, seja por se desprezarem os meios mais próprios e mais enérgicos de promover o seu lançamento, seja (o que me parece mais provável) por se ter enervado nos braços da ociosidade aquelle amor do trabalho e patriotismo, que prefere ao interesse próprio o bem comum. ${ }^{13}$

Assim, o modelo genético aplicado ao seu princípio explicativo do presente - o estado atual encontra sua origem na falta de patriotismo e de amor ao trabalho dos indivíduos que colonizaram a região - é modelado por uma compreensão pragmática da tarefa que the foi imposta pela Câmara de Vila Boa. Neste caso, além de memorialista, seu relato dialoga com a pragmática própria da vida burocrática provincial:

Mas isto mesmo que encontrei é quanto basta para fazer conhecer a vantajosa situação de Goyaz, que, ainda mesmo na maior decadência em que se considera, e a que diferentes motivos deram principio, tem proporções para se levantar, para se ressurgir, logo que se possam aplicar a seu beneficio os paternaes cuidados d'El-Rei Nosso Senhor. (...) logo que das espadas se possam forjar arados, e que se restabeleça a paz; logo que as sabias províncias d'El-Rei N. S. de mais perto atendam ás nossas necessidades, Goyas florescerá, augmentará o esplendor do throno, e se tornará a mais brilhante porção dos domínios portugueses. ${ }^{14}$

A paisagem local é percebida, então, por uma janela interior: a memória espreitava um futuro promissor, mas que tarda. Na ausência de novos fluxos econômicos, restava o laço político como estratégia para incluir a região nos acontecimentos definidores da política nacional.

Também Cunha Matos, em sua Corografia Histórica de Goiás, de 1824 descreveu o quadro de ruralização e de empobrecimento da região, figurado

13 SOUZA, Luiz Antônio da Silva e. Memória do descobrimento, governo, população e cousas mais notáveis da Capitania de Goyaz, p.71

14 SOUZA, Luiz Antônio da Silva e. Memória do descobrimento, governo, população e cousas mais notáveis da Capitania de Goyaz, p.38-139. 
sob o signo da decadência. A narrativa histórica regional permaneceu aprisionada na temporalidade do ouro e de sua crise, "descoberta e povoada por aventureiros que só procuravam riquezas". Cunha Matos não despreza o período de riqueza pelo qual passou a região, mas sua conclusão é reticente quanto às consequências positivas dessa ocupação:

A sede do ouro foi causa da descoberta de Goiás, e a esperança do outro tem sido causa de sua ruína. As riquezas prodigiosas que cobriram a face da terra na época da descoberta da província atraíram a Goiás um imenso número de aventureiros que, ou se arruinaram absolutamente por uma dissipação licenciosa ou regressaram às terras do seu nascimento carregados de gêneros preciosos, deixando na província de Goiás como únicos monumentos, que atestam a antiga glória, as imensas excavações, que se encontram por toda parte. ${ }^{15}$

"Chegar, trabalhar e enriquecer e regressar à sua pátria era o fito dos aventureiros": o passado, como uma lição a ser aprendida pelos homens do presente, ainda permanecia ativo. Era fonte de orientação para o agir, conforme pretendia demonstrar o velho militar e legítimo representante do IHGB: "Eu cumpro os meus deveres como empregado público desta província; queira Vossa Majestade Imperial mostrar-se pai de todos os goianos aplicando remédios aos males, e fazendo aproveitar os bens que nesta obra manifesta", lembra Cunha Matos na dedicatória de seu livro. Nessa historia magistra vitae a região se apresentava como projeto, como futuro. Nela residiam potencialidades infindas, aguardando o poderoso braço do Estado. A região se representava distante, isolada, decadente.

Quase meio século depois, um padrão explicativo semelhante envolve a representação historiadora de José Martins Pereira de Alencastre, em Annaes da Província de Goyaz, de 1863: "Grandes e multiplicadas causas concorreram para o atraso das capitanias: falaremos particularmente da de Goyaz, da qual nos vamos ocupar. A sua história nem é longa nem rica de episódios, mas é dolorosa de contar-se". ${ }^{16}$ A mineração continua sendo o tema a partir do qual o administrador registra sua experiência social presente. Mas a reflexão em torno da mineração é situada, para além das consequências das guerras napoleônicas, no horizonte de expectativas de Silva e Souza, ou das Guerras da Independência que, afinal, trouxeram Cunha Matos a Goiás e orientaram seus interesses investigativos e descritivos. O período da mineração está ali associado ao contexto das relações de dominação envolvendo o Império português e sua colônia na América. O atraso no desenvolvimento da Colônia não é o resultado da extração do ouro, mas sim da forma como tal atividade foi concebida, pois "entendeu o governo português dever tomar uma série de medidas, das quais resultasse

15 MATTOS, Raymundo José da Cunha. Corografia Histórica de Goiás (1824). Brasília: Sudeco, 1979, p.79. 16 ALENCASTRE, José Martins Pereira de. Annaes da Província de Goyaz (1863). Brasília: Sudeco, 1979, p.14. 
o maior proveito para si da exploração das lavras". ${ }^{17}$ Alencastre, assim, definia o passado como estranho, pois os interesses da Coroa nada tinham a ver com o dos seus súditos. Os males do presente decorriam de medidas impostas para a exploração do ouro, por parte da metrópole, tais como: a proibição de abertura de estradas, da navegação e do estabelecimento de outro tipo de indústria que não a da mineração. Tais medidas interessavam exclusivamente aos metropolitanos. Desfazia-se, assim, a comunhão de interesses que garantiu a posse desse extenso território.

A herança colonial era um fardo a ser carregado por uma população abandonada. As marcas mais profundas desse passado não foram deixadas apenas na vida material da civilização, montada sob a sombra do ouro, mas na mentalidade dos goianos: "Mas foram poucos os annos de grandeza e prosperidade; o meteoro passou, e á luz fugaz d'essa transitória grandeza sucedeu o quadro mais contristador; o deslumbramento, porém, continuou por muito tempo ainda". ${ }^{18} \mathrm{~A}$ esse quadro de estagnação das atividades econômicas não associadas à mineração, Alencastre adiciona um "mal maior, a cobiça infrene" dos homens públicos que dilapidavam os cofres do Estado e roubavam os particulares.

Estamos diante, portanto, de um presente dilatado na medida em que envolve os mesmos julgamentos observados no campo de experiência tanto do clérigo-historiador quanto do militar-historiador. O passado materialmente registrado está moralmente corrompido. Esse passado distante deixou a sensação de abandono, mas não de nostalgia, pois não há herança a ser reivindicada. "A nostalgia é a memória com a dor excluída" pondera Lowrenthal; ${ }^{19} \mathrm{em}$ Goiás a dor do passado ainda se reflete no presente. A aprendizagem desse tempo dolorido se manifesta na narrativa histórica compartilhada por esses três autores que julgam e condenam o passado, sem que seja possível dele se afastar.

\section{Uma consciência histórica da mágoa e da esperança}

Silva e Souza, Cunha Matos, Saint Hilaire, D'Alincourt, Taunay, Pohl, Camargo Fleury, Rodrigues Jardim, Alencastre: relatos construídos em diferentes tempos, com objetivos diferentes, utilizando-se de fontes diversas, mas que descrevem uma paisagem comum. É possível tomar estes relatos como indícios capazes de nos mostrar um campo de experiência compartilhado, para além do universo dialógico explícito na composição

17 ALENCASTRE, José Martins Pereira de. Annaes da Província de Goyaz, p.16.

18 "morria-se de fome, mas a mineração não parava". A esse quadro de estagnação das atividades econômicas não associadas à mineração, Alencastre adiciona um "mal maior, a cobiça infrene" dos homens públicos que dilapidavam os cofres do Estado e roubavam os particulares. ALENCASTRE, José Martins Pereira de. Annaes da Província de Goyaz, p.18.

19 LOWENTHAL, David. The past is foreign country. Cambridge: Cambridge University Press, 1997, p.8. 
desses textos. ${ }^{20}$ Esse universo compartilhado é marcado pelo sentimento de mágoa (dos homens do passado, do domínio português, da fraqueza moral dos homens do passado e do presente contínuo), mas também pela esperança (no desenvolvimento econômico, no interesse do Estado). A representação de uma distância-ruptura com a época do ouro é recorrente em Alencastre: "A mineração era o algo de todos os desejos, uma como que febre ou delírio de que os povos estavam tomados" ${ }^{21}$ Essa febre, não recorrente, mas passageira, deixou marcas no mundo vivido. Sua fluidez podia ser demonstrada pela quantidade de povoações "acanhadas e decadentes", que antes prosperavam em número, em construções e em riqueza. É importante notar que a explicação utilizada por Alencastre aprofunda os argumentos da memória da decadência. Ao citar povoados em franco processo de desaparecimento, ele questiona: "o que representam hoje os arraiais (...) que chegaram a ter pela sua influência o predicamento de freguesia?". ${ }^{22}$ A atenção ao caráter referencial do trato com o passado, com o uso e identificação das fontes utilizadas, as disposições explicativas encontradas nas notas de rodapé, o diálogo intersubjetivo com o leitor, a crítica documental e a disposição compreensiva, mesmo que apenas esboçada, são as marcas externas mais visíveis dessa obra, ainda à espera de análise mais refinada.

Mas é nela também que podemos verificar com precisão a identidade desse novo tempo, inaugurado após a crise da mineração. A importância do relato de Alencastre, portanto, reside em sua dimensão representacional, mas também existencial: estamos diante de um novo tempo. O novo, mesmo que conceituado como ruptura, caracteriza-se essencialmente pela percepção da diferença - que é temporal, mas também espacial na medida em que nos remete ao caráter estrutural da história filosófica destacada por Martius e por Cunha Matos: o necessário vínculo entre a história nacional (do Império) e o destaque do particular (da região) em sua associação com a Nação. Assim, entre a retórica da administração provincial e a reconstrução historiadora encontra-se uma continuidade que se associa à experiência social fixada em um presente contínuo vivido pelos historiadores que perceberam a diferença de seu tempo através da redefinição do espaço: a região se redefiniu como parte do império brasileiro. Tangenciando a memória e a escrita da história, esse presente contínuo sintetiza uma nova consciência histórica, caracterizada: 1) pelo reforço do vínculo com a nação, através da disposição em associar as realizações da administração da província à trajetória do estado nacional; 2) pela negativação do período colonial,

20 Saint Hilaire conheceu Silva e Souza. Cunha Matos leu Silva e Souza e os relatórios de província, assim como o fez também Alencastre.

21 ALENCASTRE, José Martins Pereira de. Annaes da Província de Goyaz, p.18.

22 ALENCASTRE, José Martins Pereira de. Annaes da Província de Goyaz, p.23. 
associado à explicação genética; e, 3) pelo critério moral utilizado para julgar o passado.

As razões justificadoras desse marcador de continuidade não podem ser buscadas na imputação de uma suposta má-fé generalizada, dos homens do passado sobre si e seu passado. Isso porque essa supersaturação da imagética negativa sobre este presente contínuo é feita para reforçar o "eu vi, eu ouvi" da intenção memorialista, descritiva e historiadora. Julgá-los como possuidores de má fé significa ignorar a dimensão veritativa dessas histórias-memórias e o caráter pragmático de seus escritos, substituindo-a por uma narrativa histórica contemporânea empiricamente contestável. Mas também não se pode ignorar que essas narrativas tematizam o surgimento e cristalização de certo tipo de consciência histórica no longo século XIX goiano, que conclama o Estado a participar da construção, não mais da Nação já esboçada, mas da Região ainda em rascunho.

A região é um lugar de embate. Político, sim, mas também identitário. Foi por esse lugar de fala que os eruditos do IHGB pelearam. Cunha Matos definiu qual o objetivo da história de seu tempo:

A história é a sciencia de narrar ou de descrever os acontecimentos presentes e os passados (...) Ella em matéria, ordem e estylo deve ser escripta por um modo harmonioso, agradável, conciso, decente, exacto e o mais claro possível. E o fim principal da historia política e civil, é encaminhar os homens á pratica das virtudes e ao aborrecimento dos vícios para que d'ahi resulte o bem estar das sociedades. ${ }^{23}$

Esse potencial pedagógico e pragmático foi tomado como modelo para a organização dos estudos históricos em Goiás. Antes da organização do IHGG, o Gabinete Literário, fundado em 1864, foi responsável pela aquisição de uma das raras bibliotecas na cidade de Goiás e, no âmbito da cultura histórica, cumpriu, em parte, as funções atribuídas ao instituto histórico no sentido de difundir as publicações, especialmente, as revistas do Instituto Histórico e Geográfico do Brasil, bem como de ordenar o campo literário de uma comunidade de leitores em região distante do mercado editorial. ${ }^{24}$

23 MATTOS, Raymundo José da Cunha. Dissertação acerca do systema de escrever a história antiga e moderna do Império do Brasil, p.137.

24 Exemplo do que ora afirmamos pode ser encontrado no debate entre Nabuco e Alencar, quando o primeiro criticava o romancista, e sua peça Os Jesuítas, pela distância entre o sentido nacional próprio ao universo alencariano e as novas concepções de mundo que se abriam no final do século. A peça foi escrita por Alencar para ser encenada nas comemorações da passagem dos quarenta anos da independência, entretanto só foi encenada, sem muito sucesso, na década seguinte. Alencar se defende da crítica, advertindo que a falta de público em sua peça decorria do interesse dos cariocas pelos estrangeirismos, mas afirmava que sentimento diverso se encontrava nas províncias. Para comprovar tal evidência comenta que a biblioteca de Goiás adquiriu, além das obras completas de sua autoria, a de J. M. de Macedo. Cf. COUTINHO, Afrânio (org). A polêmica Alencar/Nabuco. Rio de Janeiro: Tempo Brasileiro, 1978; SANDES, Noé Freire. A invenção da nação entre a monarquia e a república. 2 ed. Goiânia: Editora UFG, 2011. 
Entre o final do século XIX e as primeiras décadas do século XX, a escrita da história regional seguia os passos de uma tradição que se apressava tanto a lamentar o passado quanto a propagandear as riquezas do Estado. Consolidava-se, assim, a tradição pragmática que na República se fez presente na revista Informação Goyana, publicada no Rio de Janeiro entre os anos de 1917 e 1935. Em seu primeiro número, a revista afirmava o seu compromisso em dar visibilidade à região:

O periodismo carioca nas suas revistas dos Estados não inclue nunca o de Goyaz. Nem nos trabalhos organizados pela Diretoria de Estatística Commercial do Ministerio da Fazenda, nem nos do Serviço de Estatística Commercial do Rio de Janeiro o simples vocábulo indigena Goyaz vem mencionado. Ora, um dos principaes esforços desta revista é precisamente colocar diante dos olhos dos capitalistas, dos industriaes e dos comerciantes as possibilidades econômicas sem conta do Estado mais central e menos conhecido do Brasil. ${ }^{25}$

A recorrência às possibilidades econômicas define a espera de um novo ciclo de progresso. Na cidade de Goiás, a imagem do Anhanguera permanecia como referência de um passado que se conservava como mito de fundação, contraposto ao parco legado do período aurífero. Em 1914, foi encontrada em uma fazenda em Catalão uma cruz, supostamente pertencente à bandeira do Anhanguera, que se transformou em objeto de culto ao passado. A cruz trazia incrustada na madeira uma data referente ao século XVIII, entretanto não se podia reconhecer o último algarismo inscrito, motivo para viva polêmica: a cruz pertencera, de fato, à bandeira do Anhanguera? A relíquia se transformou em monumento, presença e ausência de um tempo imemorial. Na disputa com os paulistas pela posse da cruz do Anhanguera, a intelectualidade goiana sinalizou claramente o tipo de compromisso que desejavam assumir com o passado. Na ocasião do centenário da cidade de Goiás, em 1918, ocorreu a inauguração do monumento: a cruz do Anhanguera, incrustada nas proximidades do Rio Vermelho, consagrou a cidade centenária. ${ }^{26}$

Ainda na década de 1920, Americano do Brasil escreveu uma síntese da história de Goiás por ocasião do centenário da independência, calcada num tipo de narrativa pressionada pela tradição memorialista e pela exigência metódica. Sua Súmula de História de Goiás caracteriza-se pela mágoa e o peso de um passado difuso em que reluz o brilho do ouro e da pobreza, mas que se regozija na busca da verdade, do documento: "desfazem-se alguns fetiches do pórtico da história goiana, mas são substituídos pela realidade dos fatos, (...) defino o lugar dos bandeirantes e corrijo a injusti-

25 A informação Goyana, Rio de Janeiro, v.1, n.1, p.1, 1917

26 PINHEIRO, Antônio Cesar Caldas. Os tempos míticos das cidades-goianas: mitos de origem e invenção de tradição. Goiânia: Universidade Federal de Goiás, 2003 (História, Dissertação de Mestrado). 
ça de séculos; modifico os pormenores, mas não desmereço a história"27 O trabalho deveria ser publicado pelo IHGB em um dicionário acerca da história nacional, que não chegou a ser finalizado. A publicação da obra de Americano do Brasil ocorre em contexto diverso, em 1932 quando o interventor Pedro Ludovico ensaiava os primeiros passos para a transferência da capital goiana. ${ }^{28}$

A Súmula de História de Goiás foi adotada como manual com a criação da cadeira de História de Goiás na escola normal. Nesse livro, o autor registra um tempo distante dos conflitos do presente - muito embora este mesmo presente tenha sido tomado como ponto de inflexão sobre o passado: "a descoberta de Goiás no século XVI é uma novidade inconteste, muito a propósito de ser ensinada agora, no advento do regime de reparações e das responsabilidades: é uma justiça ao passado". ${ }^{29}$ A Súmula é, conforme anuncia o próprio título, um resumo do que deveria ser guardado pelos estudantes e homens de cultura sobre a história de Goiás. A escrita de Americano do Brasil é distinta do registro de cronistas, viajantes, e presidentes de província, mas não rompe com a matriz de Alencastre. A narrativa histórica de Americano do Brasil é marcada pela presença da crítica documental ao lado de listas de nomes de presidentes de província e de autoridades que deveriam ser lembrados. A tradição memorialística permanece, como sombra, avalizando os acertos da perspectiva metódica. Para Americano do Brasil, o historiador reúne as qualidades de um erudito - naturalista, etnólogo, político, economista e filósofo - e as de um poeta. A este último cabe superar a erudição "para fazer deste complexo um trabalho de vida onde palpite o Brasil antes de tudo e apareça, em nosso caso particular, o nome goiano, como uma copulativa de progresso, de labor e benquerença à unidade territorial". 30

Americano empreende assim o inventário da região no momento de ultrapassagem da experiência histórica por ele vivida. A mudança da capital de Goiás para Goiânia, sinalizada pelo interventor Pedro Ludovico, implicava novo deslocamento. Destituída de sua função administrativa, Goiás, a antiga capital, pairou suspensa no tempo. A cidade que antes nomeava o todo foi reduzida a condição de parte, cujo sentido exigia complemento, Goiás velho. Para a antiga capital restou o culto ao passado, assombrado pela célebre frase de Alencastre: uma história pobre em acontecimentos e

27 BRASIL, Antônio Americano do. Súmula da História de Goiás. Goiânia: SECUT, 1982, p.2

28 Também em 1932, Colemar Natal, futuro presidente do IHGG, escreveu uma História de Goiás, uma obra de caráter administrativo e institucional, em que a herança bandeirante "de honras e glórias" está articulada ao dever cívico que envolve o estudo do passado. O modelo que toma a antiga metrópole como princípio explicativo para o passado de decadência e atraso é mantido. Há que se notar, todavia, um novo compromisso que, embora insinue-se apenas na dedicatória do livro, é indicador das expectativas de mudança e portanto, a relação de forças que envolvia a reflexão sobre o passado, naquele momento: "Pedro Ludovico Teixeira - a figura máxima da Revolução no Brasil Central”. Cf. NATAL, Colemar. História de Goiás (1932). Goiânia: OGL, 2002.

29 BRASIL, Antônio Americano do. Súmula da História de Goiás, p.2.

30 BRASIL, Antônio Americano do. Súmula da História de Goiás, p.1. 
triste de se contar. Doravante, outro marcador foi inscrito no tempo histórico regional, Goiânia. A nova capital redefiniu o espaço, o tempo e a escrita da história de Goiás, enquanto a perspectiva orientadora do historiador goiano migrou para um presente distante das experiências e das expectativas de seu próprio tempo. 